\title{
Neuron-derived orphan receptor 1 transduces survival signals in neuronal cells in response to hypoxia-induced apoptotic insults
}

\author{
Chung-Ching Chio, MD, ${ }^{1,2}$ Li Wei, MD, ${ }^{3}$ Tyng Guey Chen, MD, ${ }^{4}$ Chien-Min Lin, MD, PhD, ${ }^{5}$ \\ Ja-Ping Shieh, MD, ${ }^{6}$ Poh-Shiow Yeh, MD, ${ }^{7}$ and Ruei-Ming Chen, $\mathrm{PhD}^{2,8-10}$
}

\begin{abstract}
Departments of ${ }^{1}$ Neurosurgery, ${ }^{6}$ Anesthesiology, and ${ }^{7}$ Neurology, Chi-Mei Medical Center, Tainan; ${ }^{2}$ Comprehensive Cancer Center, ${ }^{5}$ Department of Neurosurgery, ${ }^{8}$ Graduate Institute of Medical Sciences, Taipei Medical University; Departments of ${ }^{3}$ Neurosugery and ${ }^{4}$ Anesthesiology and ${ }^{~}$ Brain Disease Research Center, Wan-Fang Hospital, Taipei Medical University; and ${ }^{10}$ Anesthetics and Toxicology Research Center, Taipei Medical University Hospital, Taipei, Taiwan
\end{abstract}

\begin{abstract}
OBJECTIVE Hypoxia can induce cell death or trigger adaptive mechanisms to guarantee cell survival. Neuron-derived orphan receptor 1 (NOR-1) works as an early-response protein in response to a variety of environmental stresses. In this study, the authors evaluated the roles of NOR-1 in hypoxia-induced neuronal insults.

METHODS Neuro-2a cells were exposed to oxygen/glucose deprivation (OGD). Cell viability, cell morphology, caspase-3 activity, DNA fragmentation, and cell apoptosis were assayed to determine the mechanisms of OGD-induced neuronal insults. RNA and protein analyses were carried out to evaluate the effects of OGD on expressions of NOR-1, CAMP response element-binding (CREB), and cellular inhibitor of apoptosis protein 2 (c/AP2) genes. Translations of these gene expressions were knocked down using RNA interference. Mice subjected to traumatic brain injury (TBI) and NOR-1 was immunodetected.

RESULTS Exposure of neuro-2a cells to OGD decreased cell viability in a time-dependent manner. Additionally, OGD led to cell shrinkage, DNA fragmentation, and cell apoptosis. In parallel, treatment of neuro-2a cells with OGD time dependently increased cellular NOR-1 mRNA and protein expressions. Interestingly, administration of TBI also augmented NOR-1 levels in the impacted regions of mice. As to the mechanism, exposure to OGD increased nuclear levels of the transcription factor CREB protein. Downregulating CREB expression using RNA interference simultaneously inhibited OGD-induced NOR-1 mRNA expression. Also, levels of clAP2 mRNA and protein in neuro-2a cells were augmented by OGD. After reducing cIAP2 translation, OGD-induced cell death was reduced. Sequentially, application of NOR-1 small interfering RNA to neuro-2a cells significantly inhibited OGD-induced cIAP2 mRNA expression and concurrently alleviated hypoxia-induced alterations in cell viability, caspase-3 activation, DNA damage, and cell apoptosis.
\end{abstract}

CONCLUSIONS This study shows that NOR-1 can transduce survival signals in neuronal cells responsible for hypoxiainduced apoptotic insults through activation of a CREB/CIAP2-dependent mechanism.

KEY WORDS NOR-1; neuronal cell; hypoxia; survival signals; CREB/CIAP2; traumatic brain injury

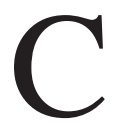

EREBRAL hypoxia is commonly caused by traumatic brain injury (TBI) and brain tumors. A prospective study reported that almost half of patients with a severe head injury had epidemiologically experienced a period of hypoxia. ${ }^{6}$ This low-oxygen condition can subsequently lead to brain edema and neurodegeneration..$^{30}$ To neurologically critically ill patients, cerebral hypoxia is further recognized as a major potential cause of secondary injury. ${ }^{22}$ Clinically, hypoxia is highly associated with a significant increase in morbidity and mortality from severe head injuries. ${ }^{22,30}$ Because brain ischemia and hypoxia are vital causes of brain damage, preservation of sufficient tissue oxygenation is a primary objective in the field of neurocritical care. ${ }^{26}$ Additionally, hypoxia has

\footnotetext{
ABBREVIATIONS cIAP2 = cellular inhibitor of apoptosis protein 2; CREB = cAMP response element-binding; DMEM = Dulbecco's modified Eagle's medium; DMSO = dimethyl sulfoxide; ELISA = enzyme-linked immunosorbent assay; GBM = glioblastoma multiforme; mAb = monoclonal antibody; NOR-1 = neuron-derived orphan receptor 1; OGD = oxygen/glucose-deprivation; RT-PCR = reverse transcription polymerase chain reaction; $p A b=$ polyclonal antibody; PAGE = polyacrylamide gel electrophoresis; $\mathrm{PBS}$ = phosphate-buffered saline; $\mathrm{PCNA}=$ proliferating cell nuclear antigen; $\mathrm{PI}$ = propidium iodide; $\mathrm{PMSF}=$ phenylmethylsulfonyl fluoride; $\mathrm{RNAi}=\mathrm{RNA}$ interference; SDS = sodium dodecyl sulfate; siRNA = small interfering RNA; TBI = traumatic brain injury.
}

SUBMITTED January 7, 2015. ACCEPTED June 3, 2015.

INCLUDE WHEN CITING Published online November 27, 2015; DOI: 10.3171/2015.6.JNS1535. 
been implicated in many characteristics of tumor development, angiogenesis, and growth. ${ }^{6}$ A low-oxygen condition can enhance tumor vascularization, mutation rate, and metastatic spread in tumor development. ${ }^{30}$ Under hypoxic stress, brain tumor cells either survive by augmenting the glycolysis rate or undergo cell death. ${ }^{7,12}$ For the highly aggressive glioblastoma multiforme (GBM), intratumoral hypoxia has been reported to be associated with resistance to radiotherapy and chemotherapy. ${ }^{15}$ Therefore, brain hypoxia plays multiple physiological and pathophysiological roles in TBIs and brain tumors.

Apoptosis, the process of programmed cell death, can occur in developing and adult animal tissues..$^{13}$ A variety of intrinsic or extrinsic molecular events can trigger the progression of cell apoptosis. When cells undergo apoptosis, specific apoptotic characteristics may appear, including a changed morphology, caspase cascade activation, DNA fragmentation, and cell cycle arrest at the sub- $\mathrm{G}_{1}$ phase. ${ }^{21,35}$ In neuronal development, because apoptosis can precisely regulate the programmed natural death of neurons, it is thought to play important roles in neurogenesis. ${ }^{14,29}$ However, premature or irregular apoptotic regulation can lead to the pathogenesis of neurodegeneration, subsequently leading to various acute or chronic brain diseases. A deviation in the supply and consumption of oxygen in brain tissues initiates hypoxic stress that causes a complex cycle of biochemical and molecular events and accordingly results in neuronal death. ${ }^{7,36}$ Our previous study showed that treatment of neural cells with oxygen/ glucose derivation (OGD) can mimic hypoxic conditions and induce cell shrinkage and cell cycle arrest at the sub$\mathrm{G}_{1}$ phase. ${ }^{7}$ Fatemi et al. reported that hypoxia-induced apoptotic insults to neonatal brains are a crucial cause of cerebral palsy, mental retardation, and epilepsy. ${ }^{11}$ To overcome hypoxia-induced adverse situations, brain neurons should adopt some cellular mechanisms such as induction of various transcription factors.

In addition to inducing cell apoptosis, hypoxia can also trigger adaptive mechanisms to guarantee cell survival. A large array of hypoxia-associated proteins is involved in hypoxic stress-induced neural damage and survival. ${ }^{31}$ Neuron-derived orphan receptor 1 (NOR-1), a member of the nuclear receptor 4A subfamily, functions as a ligandindependent transcription factor. ${ }^{39}$ NOR-1 has been reported to be an early-response protein accountable for a pleiotropy of environmental cues. ${ }^{25} \mathrm{Kim}$ et al. have shown that after transient global ischemia for 3 hours, NOR-1 is rapidly induced in the dentate gyrus of the hippocampal formation and piriform cortex..$^{17}$ In addition, exposure to hyperbaric air increases transcription of the NOR-1 gene in rat vascular tissues. ${ }^{10}$ As a transcription factor, NOR-1 can regulate certain survival-related gene expressions. ${ }^{38}$ Cellular inhibitor of apoptosis protein 2 (cIAP2), a ubiquitin ligase, has a RING domain in the carboxyl terminal that specifically binds to caspases or nuclear factor (NF) $-\kappa B$ and mediates cell survival signals. ${ }^{34,37}$ In endothelial cells, knocking down NOR-1 expression concurrently downregulated cellular cIAP2 levels and enhanced hypoxia-induced cell damage. ${ }^{24}$ Thus, cIAP2 could be a downstream target of NOR-1 in response to hypoxic stress. In this study, we evaluated the roles of NOR-1 in hypoxia-induced insults to neurons and the possible molecular mechanisms.

\section{Methods \\ Cell Culture and Hypoxia Treatment}

Mouse neuroblastoma neuro-2a cells purchased from American Type Culture Collection were cultured in Dulbecco's modified Eagle's medium (DMEM; Gibco-BRL) supplemented with $10 \%$ fetal calf serum, L-glutamine, penicillin $(100 \mathrm{IU} / \mathrm{ml})$, and streptomycin $(100 \mu \mathrm{g} / \mathrm{ml})$ in $75-\mathrm{cm}^{2}$ flasks at $37^{\circ} \mathrm{C}$ in a humidified atmosphere of $5 \%$ $\mathrm{CO}_{2}$. Cells were grown to confluence prior to drug treatment.

Neuro-2a cells were treated with OGD to induce hypoxia as described previously. Glucose-free DMEM (OGD medium) and $1 \times$ phosphate-buffered saline (PBS) (OGD buffer), containing $0.14 \mathrm{M} \mathrm{NaCl}, 2.6 \mathrm{mM} \mathrm{KCl}, 8 \mathrm{mM}$ $\mathrm{Na}_{2} \mathrm{HPO}_{4}$, and $1.5 \mathrm{mM} \mathrm{KH} \mathrm{PO}_{4}$, were prepared by bubbling with $100 \% \mathrm{~N}_{2}$ for 30 minutes. Neuro-2a cells were washed twice with OGD buffer and then seeded in OGD medium for various time intervals.

\section{Assay of Cell Viability}

Cell morphology and cell viability were assayed to evaluate the toxic effects of hypoxia to neuro-2a cells as described previously. ${ }^{19}$ Briefly, neuro-2a cells $\left(10^{4}\right.$ cells/ well) were seeded in 96-well tissue culture plates overnight. After OGD treatment, cells were cultured with new medium containing $0.5 \mathrm{mg} / \mathrm{ml} \mathrm{3-(4,5-dimethylthiazol-}$ 2-yl)-2,5-diphenyltetrazolium bromide for a further 3 hours. The blue formazan products in neuro-2a cells were dissolved in dimethyl sulfoxide (DMSO) and spectrophotometrically measured at a wavelength of $550 \mathrm{~nm}$. After OGD treatment, the cell morphology was observed and photographed using a reverse-phase microscope (Nikon).

\section{Quantification of DNA Fragmentation}

DNA fragmentation was quantified using a cellular DNA fragmentation enzyme-linked immunosorbent assay (ELISA) kit (Boehringer Mannheim) as described previously. ${ }^{20}$ Briefly, neuro-2a cells $\left(2 \times 10^{5}\right.$ cells $)$ were subcultured in 24-well tissue culture plates and labeled with BrdU overnight. Cells were harvested and suspended in culture medium. One hundred microliters of a cell suspension was added to each well of 96-well tissue culture plates. Neuro-2a cells were treated with OGD for different time intervals at $37^{\circ} \mathrm{C}$ in a humidified atmosphere of $5 \% \mathrm{CO}_{2}$. Amounts of BrdU-labeled DNA in the cytoplasm were quantified using a microplate photometer (Anthos Labtec Instruments).

\section{Quantification of Apoptotic Cells}

Cell apoptosis was quantified using propidium iodide (PI) according to a previously described method. ${ }^{8}$ After OGD treatment, neuro-2A cells were harvested and fixed in cold $80 \%$ ethanol. Following centrifugation and washing, fixed cells were stained with PI and analyzed by a flow cytometer (EPICS XL, Beckman Coulter). 


\section{Fluorogenic Substrate Assay for Caspase-3 Activity}

Caspase-3 activity was determined using a fluorometric substrate assay kit. ${ }^{5}$ Briefly, after OGD administration, neuro-2a cells were lysed using a buffer containing $1 \%$ Nonidet P-40, $200 \mathrm{mM} \mathrm{NaCl}, 20 \mathrm{mM}$ Tris/ $\mathrm{HCl}$ (pH, 7.4), $10 \mathrm{mg} / \mathrm{ml}$ leupeptin, $0.27 \mathrm{U} / \mathrm{ml}$ aprotinin, and $100 \mathrm{mM}$ phenylmethylsulfonyl fluoride (PMSF). Cell extracts (25 $\mathrm{mg}$ total protein) were incubated with $50 \mathrm{mM}$ of a specific fluorogenic peptide substrate in $200 \mathrm{~mL}$ of a cellfree system buffer composed of $10 \mathrm{mM}$ HEPES (pH 7.4), $220 \mathrm{mM}$ mannitol, $68 \mathrm{mM}$ sucrose, $2 \mathrm{mM} \mathrm{NaCl}, 2.5 \mathrm{mM}$ $\mathrm{KH}_{2} \mathrm{PO}_{4}, 0.5 \mathrm{mM}$ ethylene glycol tetraacetic acid, $2 \mathrm{mM}$ $\mathrm{MgCl}_{2}, 5 \mathrm{mM}$ pyruvate, $0.1 \mathrm{mM}$ PMSF, and $1 \mathrm{mM}$ dithiothreitol. The peptide substrate for the caspase-3 enzyme assay was DEVD. The peptide was conjugated to 7-amino-4-(trifluoromethyl)coumarin for fluorescence detection. Intensities of the fluorescent products were measured using a spectrometer.

\section{Immunoblotting Analyses of NOR-1, cIAP2, and $\beta$-Actin}

Protein analyses were carried out according to a previously described method. ${ }^{38}$ After OGD treatment, cell lysates were prepared in ice-cold radioimmunoprecipitation assay buffer (25 mM Tris-HCl [pH 7.2], $0.1 \%$ sodium dodecyl sulfate [SDS], $1 \%$ Triton X-100, $1 \%$ sodium deoxycholate, $0.15 \mathrm{M} \mathrm{NaCl}$, and $1 \mathrm{mM}$ EDTA). To avoid degradation of the cytosolic proteins by proteinases, a mixture of $1 \mathrm{mM}$ phenyl methyl sulfonyl fluoride, $1 \mathrm{mM}$ sodium orthovanadate, and $5 \mu \mathrm{g} / \mathrm{ml}$ leupeptin was added to the radioimmunoprecipitation assay buffer. Protein concentrations were quantified using a bicinchoninic acid protein assay kit (Pierce, Rockford, IL, USA). Proteins $(50 \mu \mathrm{g} / \mathrm{well})$ were subjected to SDS-polyacrylamide gel electrophoresis (PAGE), and transferred to nitrocellulose membranes. NOR-1 and cIAP2 were immunodetected using a rabbit polyclonal antibody (pAb) (Santa Cruz Biotechnology). The cellular $\beta$-actin protein was immunodetected using a mouse monoclonal antibody (mAb) against mouse $\beta$-actin (Sigma) as the internal standard. These protein bands were quantified using a digital imaging system (UVtec).

\section{Extraction of Nuclear Proteins and Immunodetection}

The amounts of nuclear $c A M P$ response elementbinding (CREB) protein were quantified following a previously described method. ${ }^{4}$ Briefly, after drug treatment, nuclear extracts of neuro-2a cells were prepared. Protein concentrations were quantified by a bicinchoninic acid protein assay kit (Pierce). Nuclear proteins $(50 \mu \mathrm{g} /$ well) were subjected to SDS-PAGE and transferred to nitrocellulose membranes. After blocking, nuclear CREB was immunodetected using a rabbit $\mathrm{pAb}$ against mouse CREB (Santa Cruz Biotechnology). Cellular proliferating cell nuclear antigen (PCNA) was immunodetected using a mouse $\mathrm{mAb}$ against mouse PCNA (Sigma) as the internal control. Intensities of the immunoreactive bands were determined using a digital imaging system (UVtec).

\section{Reverse Transcription and Quantitative Polymerase Chain Reaction Assays}

Messenger (m)RNA from neuro-2a cells exposed to OGD was prepared for reverse transcription polymerase chain reaction (RT-PCR) and quantitative PCR analyses of NOR-1, cIAP2, and $\beta$-actin mRNA. Oligonucleotides for the PCR analyses of NOR-1, cIAP2, and $\beta$-actin were designed and synthesized by Clontech Laboratories. The oligonucleotide sequences of the upstream and downstream primers for these mRNA analyses were respectively 5'-CTGCAATGGACTTGTCCTGC-3' and 5'-GAGCTTG TCGATGACAGAAG-3' for NOR-1, ${ }^{16}$ 5'-TAGAGGGAC CATCAAGGGCA-3' and 5'-CATCTGTGCTCCCGGTT CTT-3' for cIAP2, and 5'-GTGGGCCGCTCTAGGCACC AA-3' and 5'-CTCTTTGATGTCACGCACGATTTC-3' for $\beta$-actin. ${ }^{7}$ The PCR products were loaded onto a $1.8 \%$ agarose gel containing $0.1 \mu \mathrm{g} / \mathrm{ml}$ ethidium bromide and were electrophoretically separated. DNA bands were visualized and photographed under ultraviolet-light exposure. The intensities of the DNA bands in the agarose gel were quantified using a digital imaging system (UVtec). A quantitative PCR analysis was carried out using iQSYBR Green Supermix (Bio-Rad) and the MyiQ Single-Color Real-Time PCR Detection System (Bio-Rad) as described previously. ${ }^{4}$

\section{CREB, cIAP2, and NOR-1 Knockdown}

Translation of CREB and NOR-1 mRNA in neuro2a cells was knocked down using an RNA interference (RNAi) method as described previously. ${ }^{9}$ CREB, cIAP2, and NOR-1 small interfering (si)RNAs were purchased from Santa Cruz Biotechnology, which is a pool of three target-specific 20- to 25-nucleotide siRNAs designed to respectively knock down CREB, cIAP2, and NOR-1 expressions. CREB, cIAP2, and NOR-1 siRNAs were transfected into neuro-2a cells according to an siRNA transfection protocol provided by Santa Cruz Biotechnology. Briefly, after culturing neuro-2a cells in antibiotic-free DMEM at $37^{\circ} \mathrm{C}$ in a humidified atmosphere of $5 \% \mathrm{CO}_{2}$ for 24 hours, the siRNA duplex solution, which was diluted in siRNA transfection medium (Santa Cruz Biotechnology), was added to neuro-2a cells. After transfection for 24 hours, the medium was replaced with normal RPMI medium, and neuro-2a cells were treated with drugs. Scrambled siRNA, purchased from Santa Cruz Biotechnology, was applied to neuro-2a cells as a negative standard.

\section{Animal Model of TBI}

Male ICR mice (weighting 20-25 g) were purchased from the Animal Center of the College of Medicine, National Taiwan University. All procedures were performed following the National Institutes of Health Guidelines for the Use of Laboratory Animals and approved by the Institutional Animal Care and Use Committee of Taipei Medical University, Taipei, Taiwan. Before the experiments began, the mice were allowed to acclimatize for 1 week in their animal quarters with air conditioning and an automatically controlled photoperiod of 12 hours of light daily. The animal was anesthetized and placed in a stereotactic frame, and its head was positioned in the horizontal plane with the nose bar set at zero. Following a midline incision exposing the skull, a 4-mm craniotomy was made lateral to the sagittal suture. The impactor tip diameter was 3 $\mathrm{mm}$. The impact velocity and the depth of cortical defor- 
mation were set at $3.5 \mathrm{~m} / \mathrm{sec}$ and $1.0 \mathrm{~mm}$, respectively. After injury, the skin was sutured and the animal was placed in an incubator until consciousness was regained.

\section{Immunohistochemical and Immunoblotting Analyses of NOR-1}

After TBI administration, the mice were killed and the brains were removed for immunohistological and immunoblotting assays. ${ }^{4}$ For immunohistological analyses, the brain tissues were fixed with a fixing reagent (acetone: methanol, 1:1). Following slicing and rehydration, the brain specimens were incubated with $0.2 \%$ Triton X-100. A rabbit pAb against mouse NOR-1 (Santa Cruz Biotechnology) was used for immunohistological detection of NOR-1. For immunoblotting analyses, the brains were homogenized with lysis buffer (50 mM Tris- $\mathrm{HCl}$ [pH 7.4], $150 \mathrm{mM} \mathrm{NaCl}, 1 \mathrm{mM}$ ethylene glycol tetraacetic acid, $1 \%$ NP-40 supplemented with $1 \mathrm{mM}$ PMSF, $1 \mu \mathrm{M}$ aprotinin, $1 \mu \mathrm{M}$ leupeptin, $1 \mathrm{mM} \mathrm{Na} \mathrm{VO}_{4}$, and $1 \mathrm{mM} \mathrm{NaF}$ ). Protein concentrations were quantified using a bicinchoninic acid protein assay kit (Pierce). Proteins $(50 \mu \mathrm{g} /$ well) were subjected to SDS-PAGE and transferred to nitrocellulose membranes. NOR-1 protein was immunodetected using a pAB (Santa Cruz Biotechnology). $\beta$-Actin was detected using a mouse $\mathrm{mAb}$ against mouse $\beta$-actin (Sigma) as an internal control. Intensities of these protein bands were determined using a digital imaging system (UVtec).

\section{Statistical Analysis}

Statistical differences between the control and OGDtreated groups were considered significant when the $p$ value of a one-way ANOVA with the Bonferroni multiplecomparison test was $<0.05$.

\section{Results}

\section{Hypoxia Induces Apoptotic Insults to Neuro-2a Cells}

To evaluate the effects of hypoxia on neuronal insults and the possible death mechanism, cell morphology, cell viability, DNA fragmentation, and apoptotic cells were analyzed (Fig. 1). Exposure of neuro-2a cells to OGD for 1 hour decreased cell number and induced a change in morphology (Fig. 1A). At 3, 6, 12, and 24 hours after OGD administration, the insults to neuro-2a cells became more aggressive. Analysis of cell viability further showed that treatment of neuro-2a cells with OGD for $1,3,6,12$, and 24 hours caused significant decreases in cell survival by $12 \%, 31 \%, 45 \%, 69 \%$, and $88 \%$, respectively (Fig. 1B). As to the mechanism, exposure of neuro2a cells to OGD for 1 hour induced DNA fragmentation by $33 \%$ (Fig. 1C). Administration of OGD for $3,6,12$, and 24 hours led to $80 \%$, $173 \%, 233 \%$, and $227 \%$ induction of DNA fragmentation in neuro-2a cells. In parallel, OGD treatment for 1 hour caused $12 \%$ of neuro-2a cells to undergo apoptosis (Fig. 1D). After exposure to OGD for 3, 6, 12, and 24 hours, the percentages of apoptotic cells were significantly raised by $29 \%, 45 \%, 81 \%$, and $89 \%$, respectively.

\section{Hypoxia and TBI Induce NOR-1 Gene Expression}

Protein and RNA analyses were conducted to determine the effects of hypoxia on NOR-1 gene expression (Fig. 2). Treatment of neuro-2a cells with OGD for 1 hour increased cellular NOR-1 levels (Fig. 2A Lane 2). After being exposed to OGD for 3 and 6 hours, amounts of NOR-1 were more augmented (Fig. 2A, Lanes 3 and 4). $\beta$-Actin was immunodetected as the internal standard (Fig. 2A). These immunorelated protein bands were quantified and statistically analyzed (Fig. 2B). Exposure of neuro-2a cells for 1,3, and 6 hours caused significant 59\%, 96\%, and $134 \%$ augmentations of cellular NOR-1 amounts, respectively. RT-PCR analyses revealed that administration of OGD for 1 hour induced NOR-1 mRNA expression (Fig. 2C Lane 2). At 3 and 6 hours after exposure to OGD, NOR-1 mRNA in neuro-2a cells was induced (Lanes 3 and 4). $\beta$-Actin mRNA was assayed as the internal standard (bottom panel). These DNA bands were quantified and statistically analyzed (Fig. 2D). Treatment of neuro-2a cells with OGD for 1,3 , and 6 hours induced NOR-1 expression by $103 \%, 132 \%$, and $92 \%$, respectively. The effects of OGD on NOR-1 mRNA expression were further confirmed using quantitative PCR (Fig. 2E). Exposure of neuro-2a cells to OGD for 1, 3, and 6 hours led to $32 \%, 95 \%$, and $110 \%$ enhancements in levels of NOR-1 mRNA, respectively.

Mice received a TBI and NOR-1 was immunodetected (Fig. 2F). Compared with sham groups, treatment of mice with TBI obviously increased levels of NOR-1 in the impacted regions. Results of an immunoblotting analysis also revealed that TBI enhanced NOR-1 production in mouse brains (Fig. 2F). $\beta$-Actin was measured as an internal control. These protein bands were quantified and statistically analyzed (Fig. 2F). Administration of TBI caused a 2.2fold increase in NOR-1 protein in the impacted regions compared with sham groups.

\section{CREB Participates in Regulation of Hypoxia-Induced NOR-1 Gene Expression}

Roles of transcription factor CREB in regulation of hypoxia-induced $N O R-1$ gene expression were assessed (Fig. 3). Exposure of neuro-2a cells to OGD for 1,3, and 6 hours obviously enhanced nuclear CREB levels (Fig. 3A, Lanes $2-4)$. $\beta$-Actin was determined as the internal standard. These protein bands were quantified and statistically analyzed (Fig. 3B). Treatment of neuro-2a cells with OGD for 1,3 , and 6 hours significantly increased amounts of nuclear CREB by $91 \%, 109 \%$, and $101 \%$, respectively. Application of CREB siRNA to neuro-2a cells suppressed translation of cellular CREB (Fig. 3C, Lane 2). Levels of $\beta$-actin were analyzed as the internal standard. These protein bands were quantified and statistically analyzed. When applying CREB siRNA to neuro-2a cells, translation of this transcription factor decreased by $79 \%$. The effects of CREB knockdown on OGD-induced NOR-1 mRNA expression were further evaluated (Fig. 3D). OGD led to 2.2-fold increase of NOR-1 mRNA in neuro-2a cells. CREB siRNA did not influence basal levels of NOR-1 mRNA. However, treatment of neuro-2a cells with CREB siRNA caused a significant $83 \%$ decrease in OGD-induced NOR-1 mRNA expression (Fig. 3D).

\section{cIAP2 Is Induced by Hypoxia and Adjusts Cell Survival}

RNA and protein analyses were carried out to deter- 

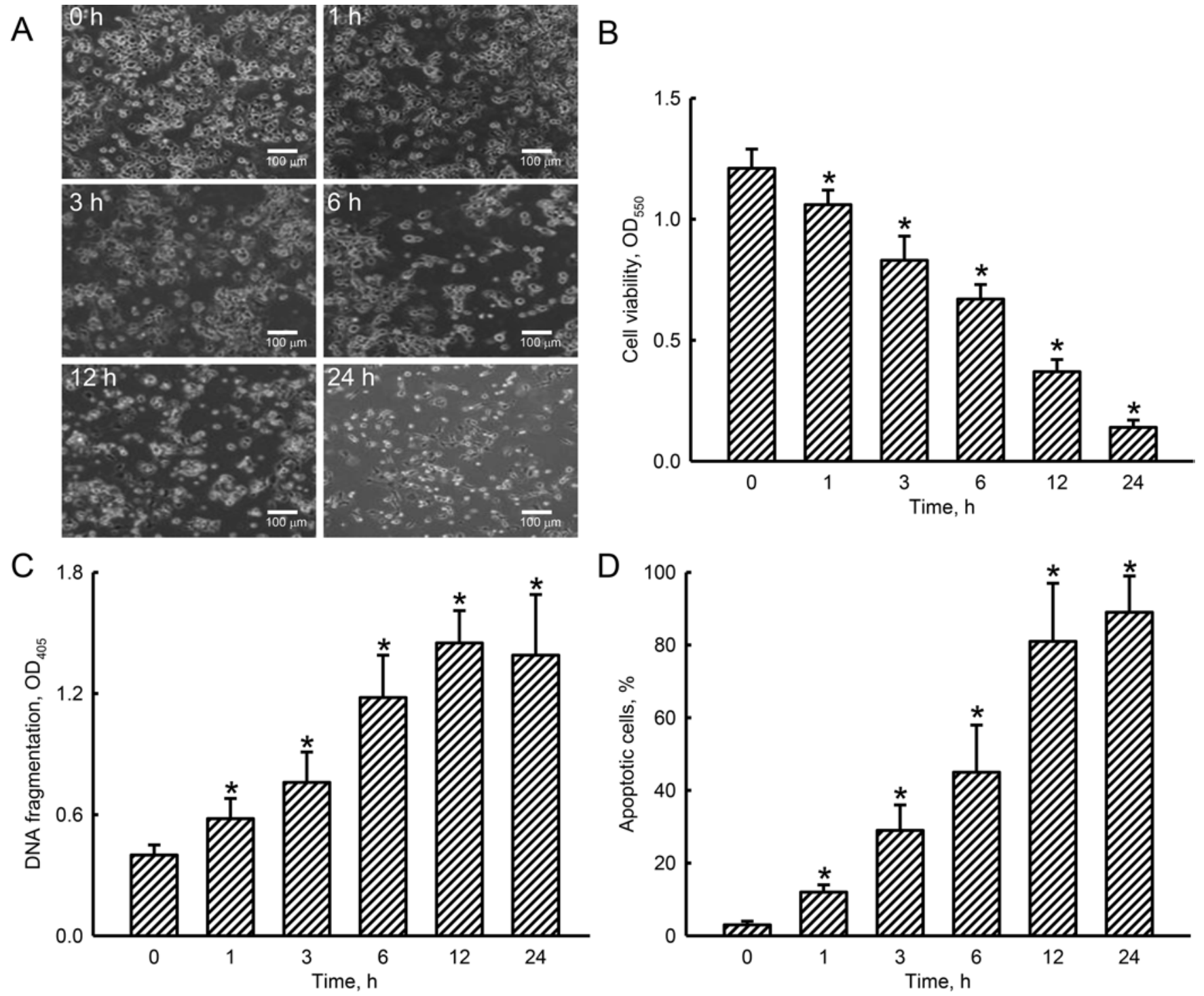

FIG. 1. Effect of hypoxia on neuronal insults. A: Neuro-2a cells were exposed to OGD for 1, 3, 6, 12, and 24 hours. Cell morphology was analyzed using a light microscope. Original magnification $\times 100$. B: Cell viability was determined by a colorimetric method. C: DNA fragmentation was quantified using ELISA. D: Apoptotic cells were quantified using a flow cytometer. Each value represents the mean \pm SEM for $n=6$. *Values significantly differed from those of the respective control $(p<0.05)$. OD = optical density.

mine the effects of hypoxia on regulation of $c I A P 2$ gene expression (Fig. 4). Exposure of neuro-2a cells to OGD for 1 hour slightly increased levels of cellular cIAP2 (Fig. 4A, Lane 2). In comparison, after OGD administration for 3 and 6 hours, amounts of cIAP2 in neuro- 2 a cells were increased (Lanes 3 and 4). $\beta$-Actin was detected as the internal control (bottom panel). These protein bands were quantified and statistically analyzed (Fig. 4B). Treatment of neuro-2a cells with OGD for 3 and 6 hours caused significant increases-93\% and 89\% -in cellular cIAP2 protein levels. Quantitative PCR analyses further demonstrated that exposure of neuro-2a cells to OGD for 1 hour did not affect cIAP2 mRNA expression (Fig. 4C). However, 3 and 6 hours after treatment with OGD, cIAP2 mRNA syntheses were increased by $68 \%$ and $94 \%$, respectively. Knocking down cIAP2 expression caused a significant in- crease (by 75\%) in OGD-induced death of neuro-2a cells (Fig. 4D).

\section{NOR-1 Transcriptionally Regulates cIAP2 Gene Expression}

Translation of NOR-1 gene expression was knocked down to determine the role of this survival protein in regulation of $c I A P 2$ gene expression (Fig. 5). Application of NOR-1 siRNA into neuro-2a cells obviously reduced levels of cellular NOR-1 protein (Fig. 5A Lane 2). $\beta$-Actin was quantified as the internal standard. These protein bands were quantified and statistically analyzed (Fig. 5B). Treatment of neuro-2a cells with NOR-1 siRNA led to a $92 \%$ reduction in translation of this survival protein. Exposure to OGD increased cIAP2 mRNA expression by 2.1-fold (Fig. 5C). NOR-1 siRNA did not change basal lev- 
A

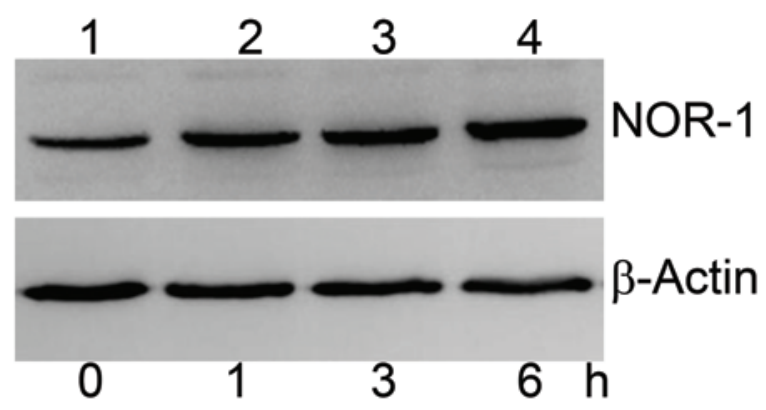

C

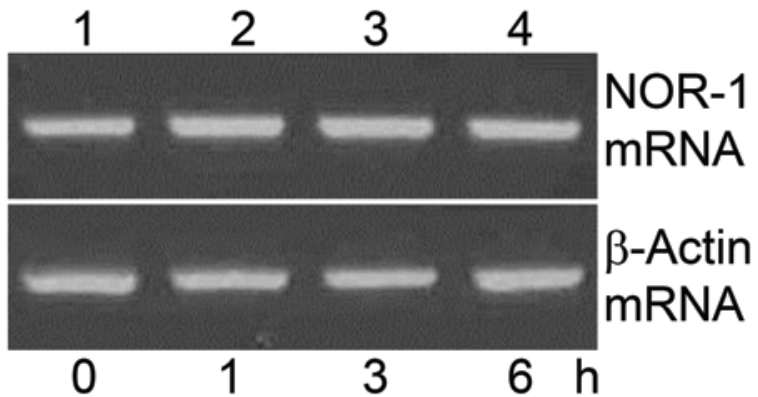

$E$

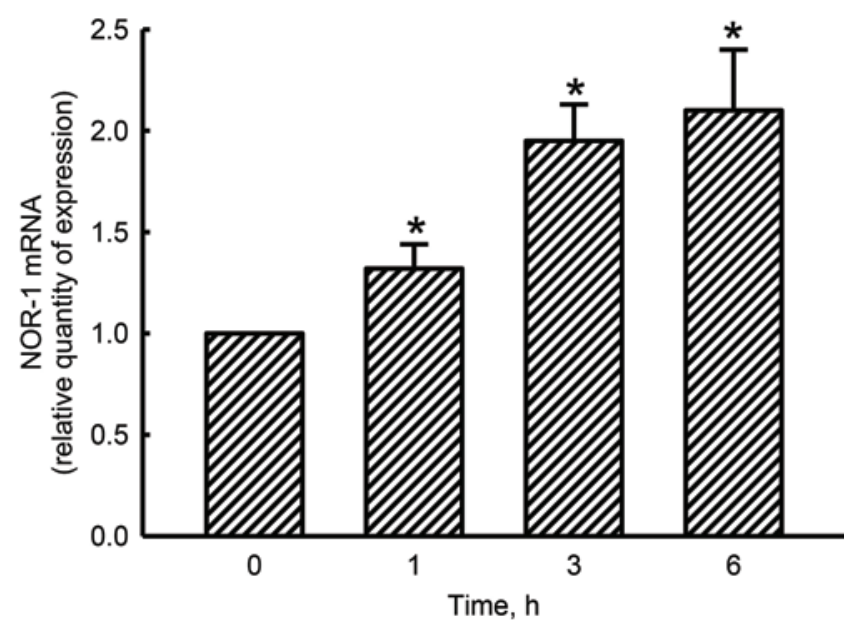

B
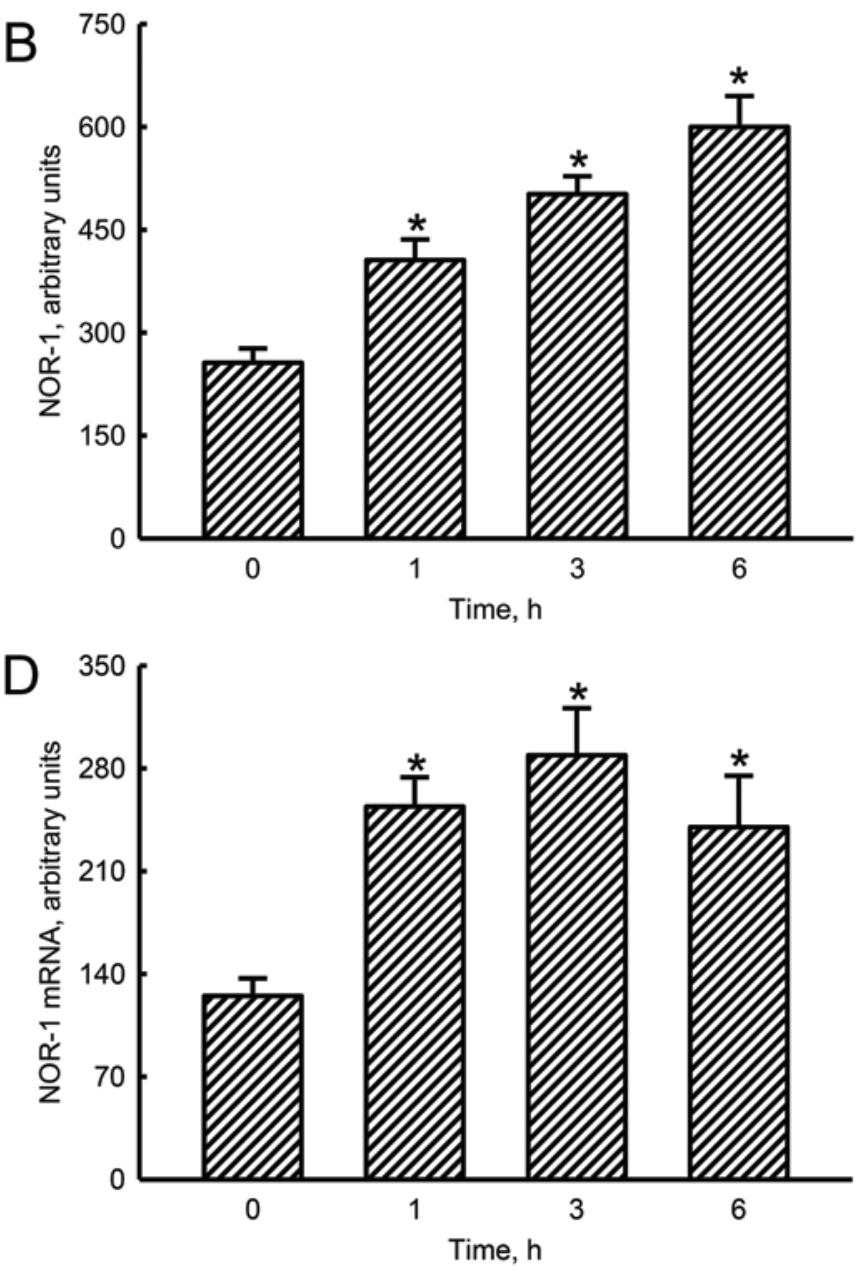

F Sham
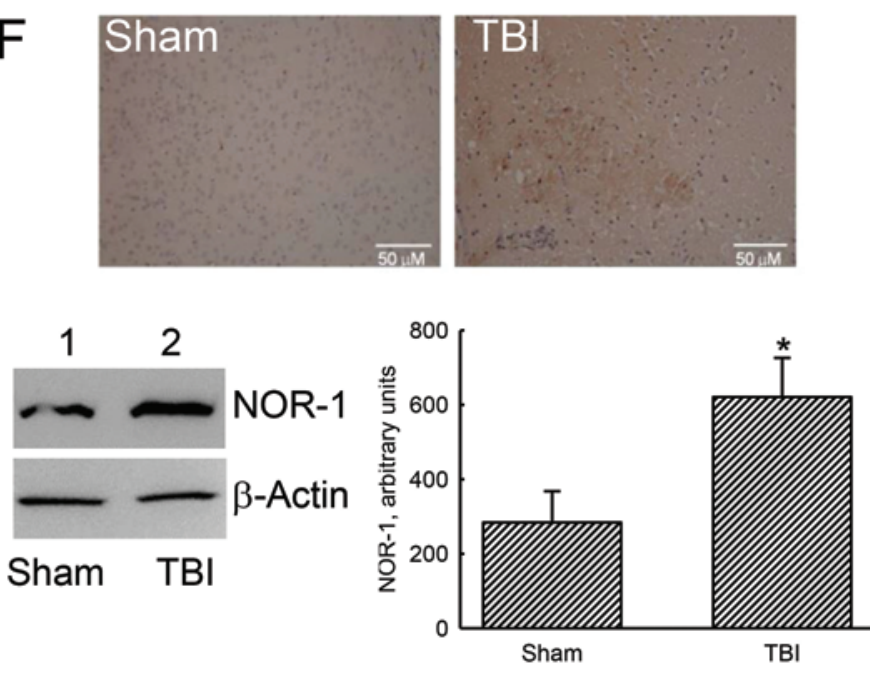

FIG. 2. Effect of hypoxia and TBI on NOR-1 expression. Neuro-2a cells were exposed to OGD for 1, 3, and 6 hours. Amounts of NOR-1 were immunodetected (A, upper panel). $\beta$-Actin was detected as the internal standard (lower panel). These protein bands were quantified and statistically analyzed (B). Levels of NOR-1 mRNA were analyzed using RT-PCR (C, upper panel). $\beta$-Actin mRNA was measured as the internal standard (lower panel). These DNA bands were quantified and statistically analyzed (D). NOR-1 mRNA was further quantified using a quantitative PCR analysis (E). Mice received a TBI, and NOR-1 was analyzed using immunohistological and immunoblotting assays $(F)$. Nuclei were stained with hematoxylin. Original magnification $\times 100$. Each value represents the mean \pm SEM $(n=6)$. *Values significantly differed from those of the respective control $(p<0.05)$. Figure is available in color online only. 
A

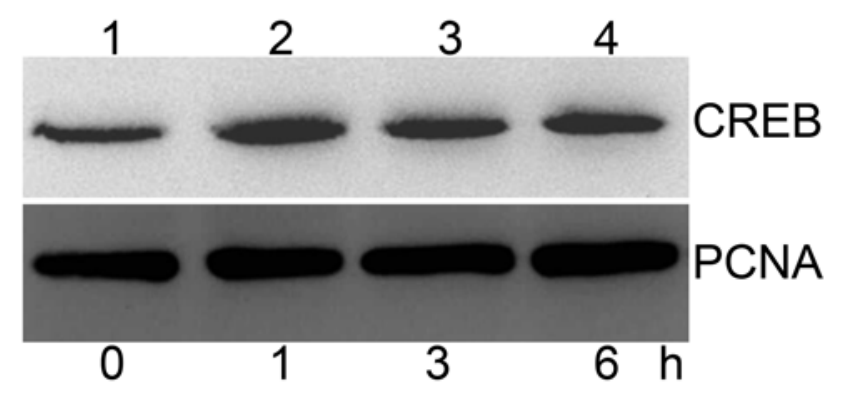

C 1
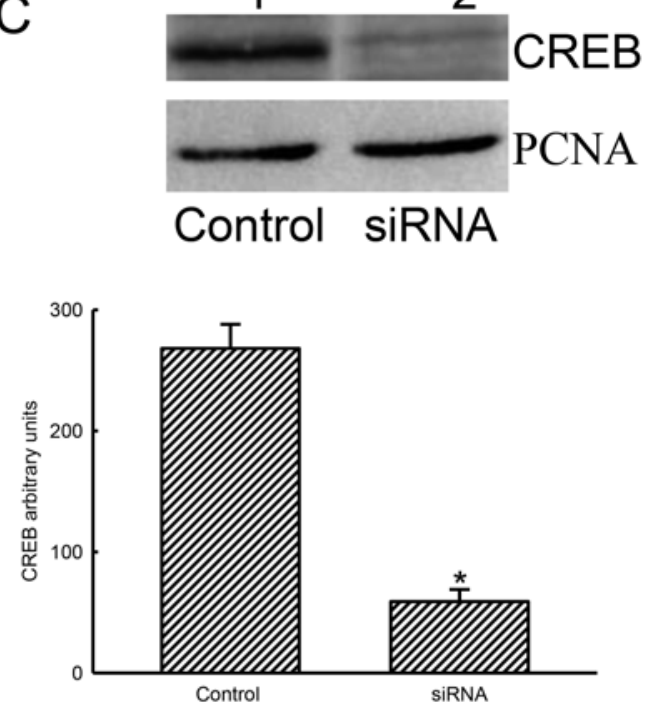

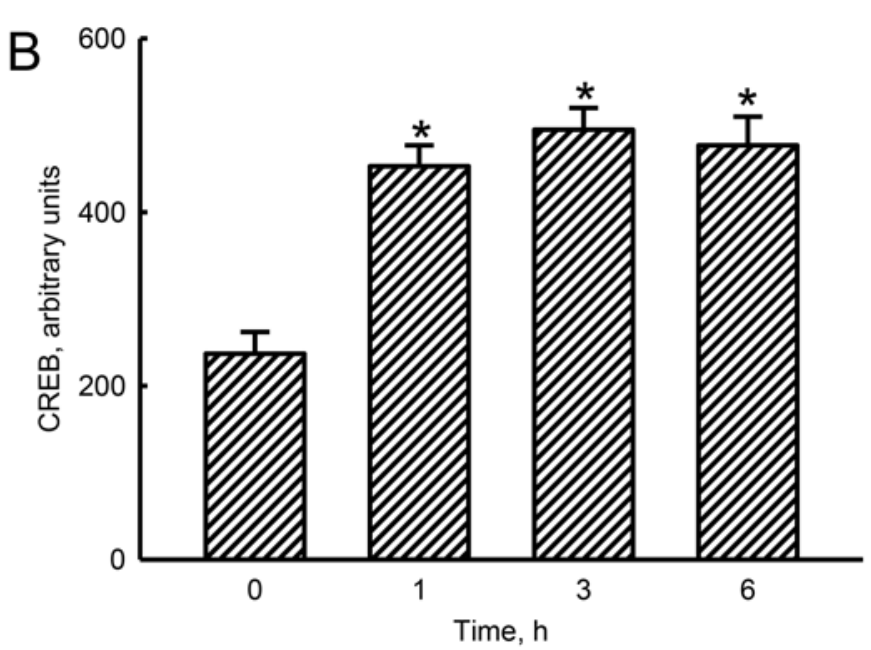

D

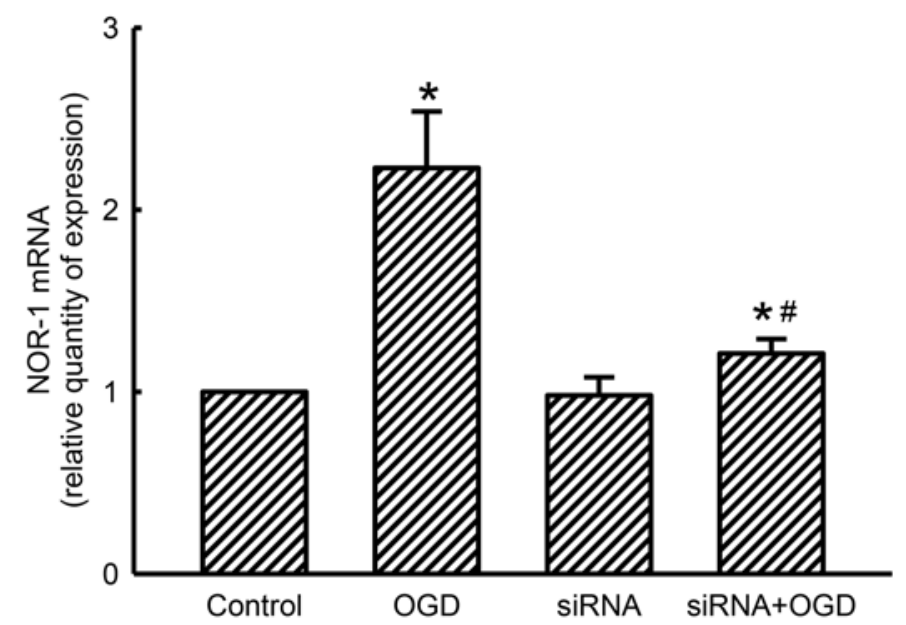

FIG. 3. Roles of CREB in hypoxia-induced NOR-1 mRNA expression. Neuro-2a cells were exposed to OGD for 1, 3, and 6 hours. Levels of nuclear CREB were immunodetected (A, upper panel). Amounts of PCNA were measured as the internal standard (lower panel). These protein bands were quantified and statistically analyzed (B). Neuro-2a cells were exposed to CREB siRNA (siRNA) for 48 hours. Control cells received scrambled siRNA. Levels of nuclear CREB were immunodetected (C, upper panel). PCNA was measured as the internal standard. These protein bands were quantified and statistically analyzed (lower panel). Neuro-2a cells were treated with OGD, CREB siRNA (siRNA), and a combination of siRNA and OGD for 6 hours. Levels of NOR-1 mRNA were analyzed using a quantitative PCR (D). Each value in the bar graph represents the mean \pm SEM $(n=6)$. *\#Values significantly $(p<$ 0.05 ) differed from those of the control and OGD-treated groups, respectively.

els of cIAP2 mRNA in neuro-2a cells. However, application of it lowered OGD-induced cIAP2 mRNA expression by $70 \%$ (Fig. 5C).

\section{NOR-1 Transduces Survival Signals in Hypoxia-Induced Apoptotic Insults}

Roles of NOR-1 in mediating survival signals were also determined (Fig. 6). Exposure of neuro-2a cells to OGD decreased $46 \%$ of cell viability (Fig. 6A). NOR-1 siRNA did not affect cell viability. However, application of NOR1 siRNA to neuro-2a cells increased OGD-induced cell death by $71 \%$ (Fig. 6A). As to the mechanism, administration of OGD to neuro-2a cells caused significant increases in caspase- 3 activity and DNA fragmentation by $180 \%$ and 96\%, respectively (Fig. 6B and C). NOR-1 siRNA alone neither changed caspase-3 activity nor induced DNA frag- mentation. In comparison, application of NOR-1 siRNA caused significant increases in OGD-induced alterations in caspase- 3 activation and DNA damage by $52 \%$ and $49 \%$, respectively (Fig. 6B and C). Consequently, the OGD-induced apoptosis of neuro-2a cells was augmented by NOR-1 siRNA by $68 \%$ (Fig. 6D).

\section{Discussion}

This study showed that NOR-1 can transduce survival signals in neuronal cells responsible for hypoxia-induced insults. Exposure of neuro-2a cells to OGD led to cell death. In parallel, NOR-1 was rapidly induced in neuro2 a cells responsible for OGD stimulation. Application of NOR-1 siRNA to neuro-2a cells decreased the production of this emergent protein and concurrently alleviated OGDinduced neuronal death. Previous functional studies have 
A
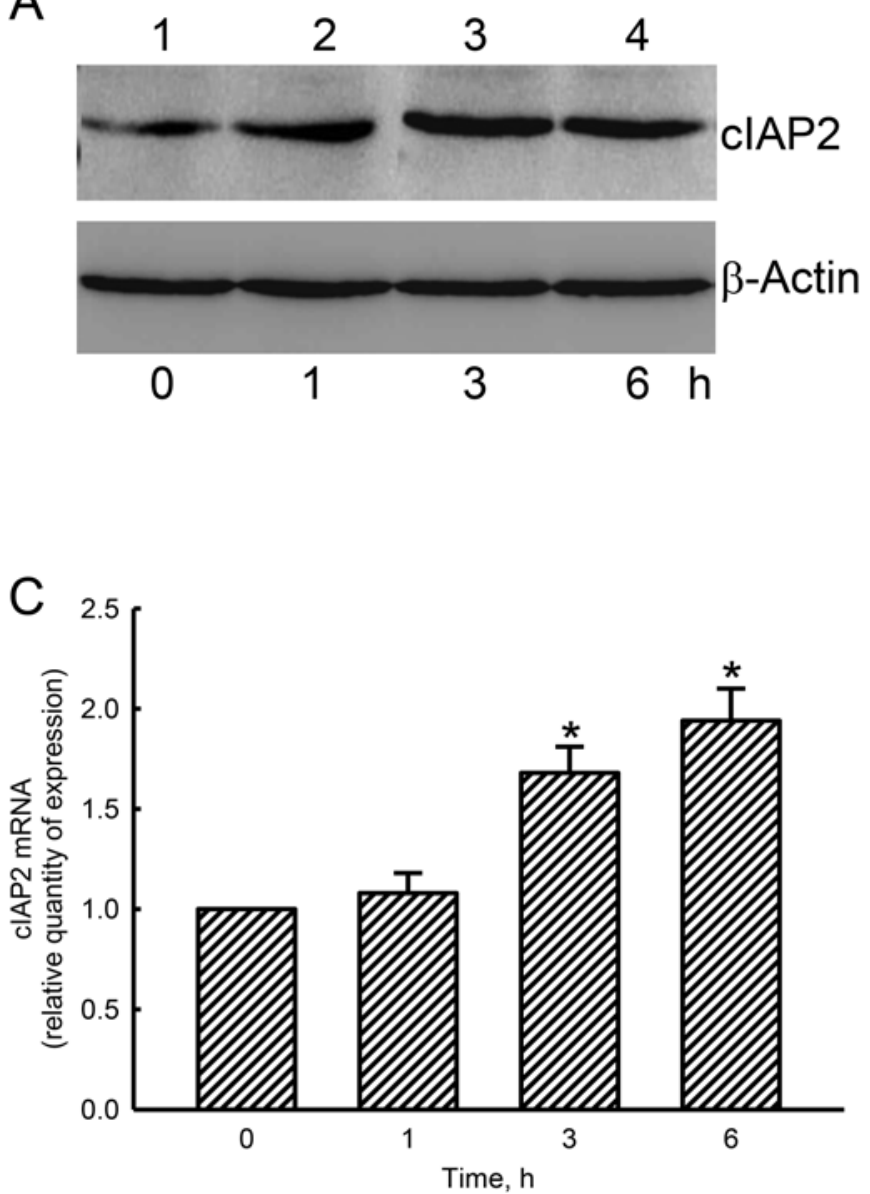
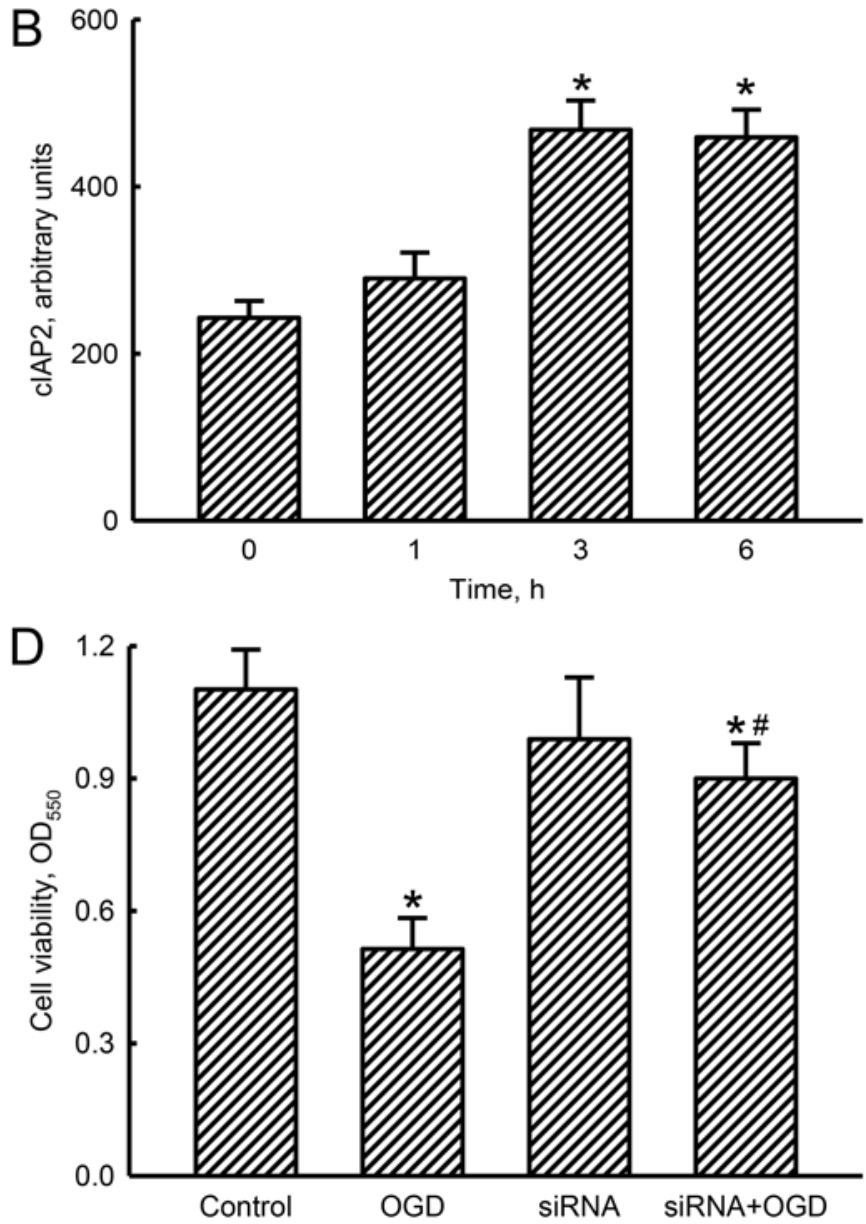

FIG. 4. Roles of cIAP2 in hypoxia-induced neuronal insults. Neuro-2a cells were exposed to OGD for 1,3 , and 6 hours. Levels of clAP2 were immunodetected (A, upper panel). Amounts of $\beta$-actin were detected as the internal standard (lower panel). These protein bands were quantified and statistically analyzed (B). Levels of cIAP2 mRNA were analyzed using quantitative PCR analyses (C). Neuro-2a cells were exposed to cIAP2 siRNA (siRNA) for 48 hours and then treated with OGD, and a combination of OGD and siRNA for 6 hours. Scrambled siRNA was administered to control cells as the negative control. Cell viability was determined by a colorimetric method (D). Each value represents the mean \pm SEM $(n=6)$. Each value represents the mean $\pm S E M(n=6)$. *\#Values significantly $(p<0.05)$ differed from those of the control and OGD-treated groups, respectively.

shown that NOR-1 participates in regulating cell proliferation, apoptosis, and differentiation. ${ }^{23,39}$ In particular, NOR1 can be rapidly induced by a pleiotropy of stimuli such as inflammatory cytokines and growth factors. ${ }^{24}$ The present results revealed that TBI could increase NOR-1 production in the impacted regions of mouse brain tissues. Cerebral hypoxia is a typical stress that commonly occurs in cases of TBI and brain tumors. In severe head injuries, hypoxia has been shown to be highly associated with significant increases in morbidity and mortality rates ${ }^{6,30}$ In addition, hypoxic conditions can enhance tumor vascularization, the mutation rate, and metastatic spread during development of brain tumors. ${ }^{1}$ As a result, preserving sufficient tissue oxygenation is a primary objective in the field of neurocritical care. ${ }^{26}$ Hypoxia can induce cell apoptosis and also trigger adaptive mechanisms to guarantee cell survival. The present study demonstrated that NOR- 1 is an early response gene in neuronal cells under low-oxygen conditions. Clinically, NOR-1 can be applied as an immediate indicator of the prognosis and diagnosis of brain diseases such as TBIs and brain tumors.
NOR-1 transduces neural survival via an antiapoptotic mechanism. Exposure of neuro-2a cells to OGD induced cell shrinkage, DNA fragmentation, and cell cycle arrest at the sub- $\mathrm{G}_{1}$ phase. A change in morphology, DNA damage, and cell cycle arrest are characteristic features of cells undergoing apoptosis. ${ }^{13,21,35}$ In addition, OGD activated caspase-3 in neuro-2a cells. Caspase-3 plays a key role in triggering intrinsic and extrinsic cell apoptosis. ${ }^{13}$ Thus, OGD can trigger low-oxygen conditions and subsequently induce the death of neuro-2a cells via an apoptotic pathway. On the other hand, when knocking down NOR1 expression using RNAi, OGD-induced modifications of these apoptotic features were simultaneously attenuated. A previous study showed that induction of NOR-1 gene expression was associated with cadmium-induced apoptosis of human peripheral blood mononuclear cells. ${ }^{33}$ Nomiyama et al. reported that in smooth muscle cells a NOR-1 deficiency decreased cell proliferation and elevated serum deprivation-induced apoptotic insults. ${ }^{28}$ In contrast, overexpression of NOR-1 can lessen low-oxygen conditioninduced apoptosis of endothelial cells. ${ }^{24}$ In this study, we 
A

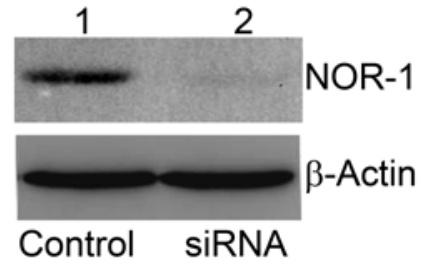

B
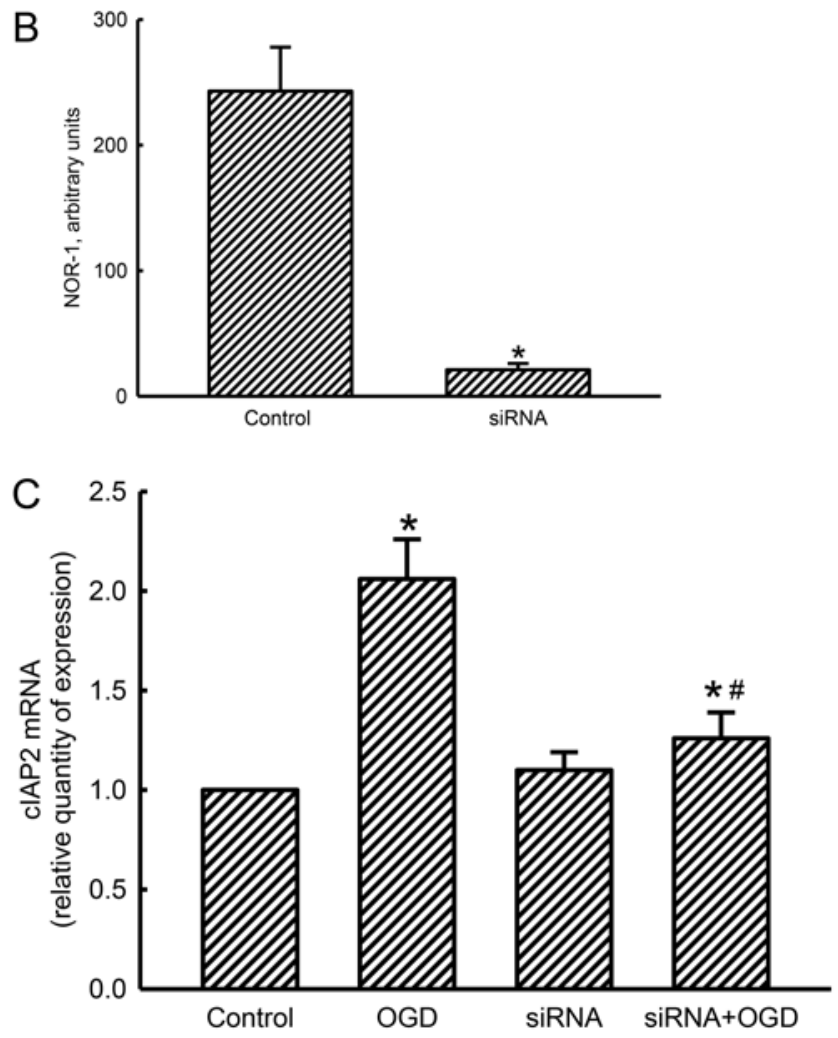

FIG. 5. Participation of NOR-1 in regulation of clAP2 mRNA expression. NOR-1 siRNA was administered to neuro-2a cells for 48 hours. Control cells received scrambled siRNA as the negative control. Levels of NOR1 were immunodetected (A, upper panel). $\beta$-Actin was quantified as the internal standard (lower panel). These protein bands were quantified and statistically analyzed (B). Neuro-2a cells were exposed to OGD, NOR1 siRNA (siRNA), and a combination of OGD and siRNA for 6 hours. NOR-1 mRNA was analyzed using quantitative PCR (C). Each value represents the mean \pm SEM $(n=6)$. *\#Values significantly $(p<0.05)$ differed from those of the control and OGD-treated groups, respectively.

further showed that NOR-1 can transduce survival signals in hypoxia-induced neuronal insults through an antiapoptotic mechanism.

CREB participates in regulating NOR-1 gene expression. The present study demonstrated that, after exposure to OGD, levels of nuclear CREB in neuro-2a cells were augmented in a time-dependent manner. Being a transcription factor, phosphorylated CREB in nuclei is capable of specifically binding to the cAMP response elements that exist in the 5'-promoter regions of certain genes and, afterward, of transcriptionally adapting these gene expressions in response to intracellular and extracellular stimuli. ${ }^{27}$ CREB has been shown to play an important role in regulating neuronal activities. ${ }^{2}$ In the ischemic brain, CREB activation consequently induces antiapoptotic $B c l-2$ gene expression that contributes to neuron survival and protection. ${ }^{18}$ In the present study, we demonstrated that knocking down CREB translation decreased production of this transcription factor and concomitantly inhibited NOR-1 mRNA expression. Rius et al. reported that in vascular smooth muscle cells, treatment with a dominant-negative of CREB or initiation of a specific mutation in the cAMP response element present in the NOR-1 promoter abolished low-density lipoprotein-induced NOR-1 promoter activity. ${ }^{32}$ As a result, this study showed that CREB can function as a transcription factor to regulate NOR-1 gene expression in neuronal cells responsible for hypoxic stress.

In response to hypoxia-induced apoptotic insults, NOR1 can act as a transcriptional factor to regulate cIAP2 gene expression in neuronal cells. Our results indicate that exposure of neuro-2a cells to OGD time-dependently induced expression of cIAP2 mRNA and protein. In addition, when RNAi techniques were used to reduce amounts of cIAP2 in neuro-2a cells, the OGD-induced decrease in cell viability was simultaneously attenuated. Previous studies have shown that cIAP2 binds to apoptosis-related proteins such as nuclear factor $-\kappa \mathrm{B}$, then suppresses caspase activity, and accordingly protects against cell death. ${ }^{34,37}$ Thus, cIAP2 may be a survival protein that mediates survival signals during the processing of hypoxia-induced insults to neuronal cells. Interestingly, our present data show that application of NOR-1 siRNA to neuro-2a cells significantly decreased levels of this transcription factor, while simultaneously inhibiting cIAP2 mRNA expression. Martorell et al. have reported that attenuating NOR-1 levels in endothelial cells caused a noteworthy downregulation of cIAP2 mRNA production. ${ }^{24}$ NOR-1 comprises an evolutionarily ancient and highly conserved group of transcription factors that can regulate certain survival-related gene expressions. ${ }^{23}$ In this study, we provide in vitro data to demonstrate that NOR-1 can protect neuronal cells against hypoxia-induced apoptotic insults by transcriptionally regulating cIAP-2 gene expression.

\section{Conclusions}

This study shows that exposure of neuro-2a cells to OGD decreased cell viability and induced DNA fragmentation and cell apoptosis in a time-dependent manner. In parallel, OGD time-dependently triggered NOR-1 mRNA and protein expression. Additionally, TBI increased amounts of NOR-1 in the impacted regions. As to the mechanism, the levels of nuclear CREB were augmented in neuro-2a cells, and application of CREB siRNA decreased amounts of this transcription factor and concurrently inhibited OGDinduced NOR-1 mRNA expression. Thus, CREB works as a transcription factor to regulate NOR-1 gene expression in OGD-treated neuronal cells. In addition, exposure of neuro-2a cells induced cIAP2 mRNA and protein expression. Knocking down cIAP2 expression augmented OGD-induced death of neuro-2a cells. Interestingly, attenuation of NOR-1 translation using RNAi concomitantly decreased levels of cIAP2 mRNA. Consequently, when knocking down NOR-1 translation, the OGD-induced reduction of cell viability was furthered, and caspase-3 activation, DNA fragmentation, and cell apoptosis were simultaneously increased. Therefore, this study demonstrated that 

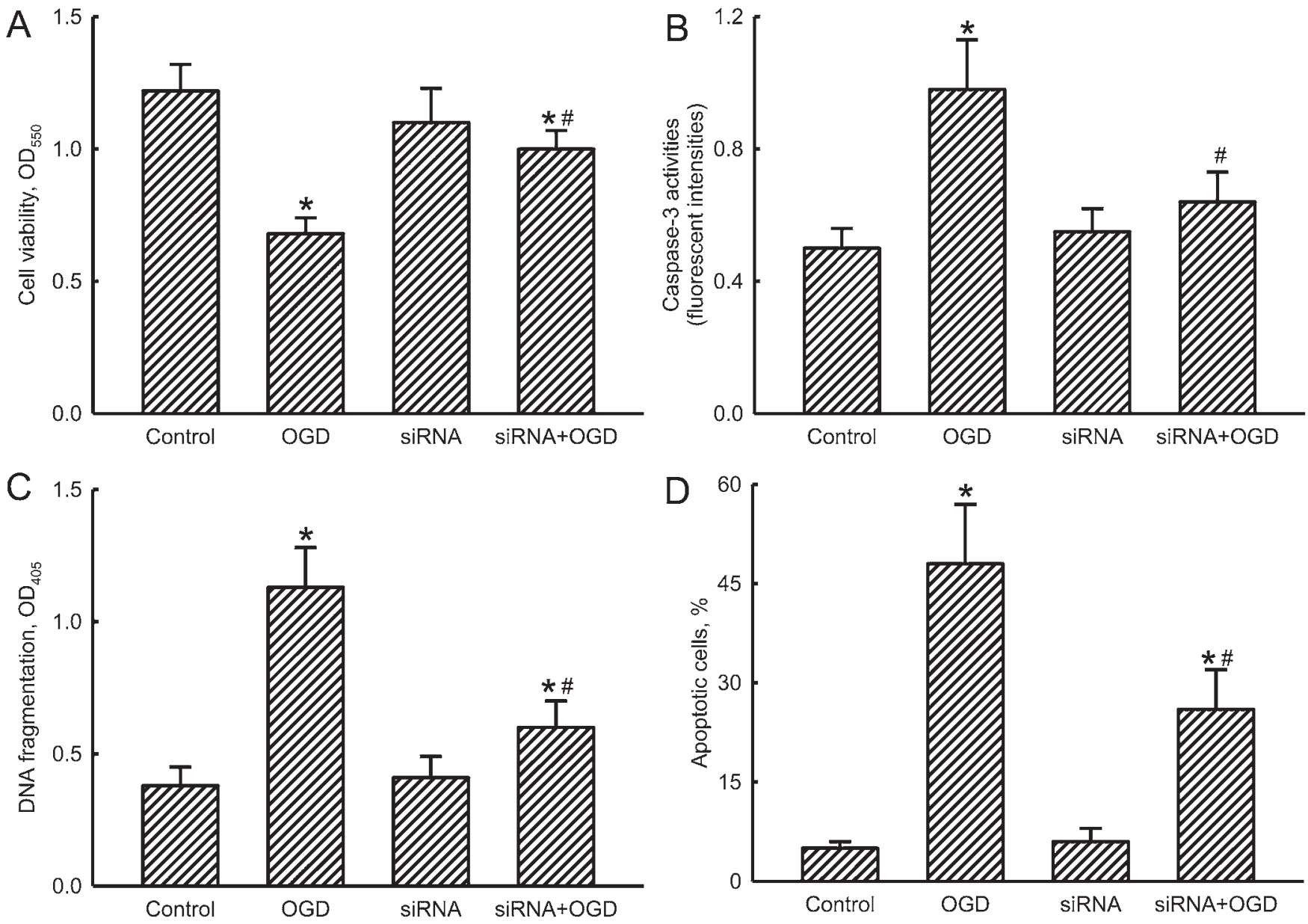

FIG. 6. Roles of NOR-1 in OGD-induced apoptotic insults to neuronal cells. Neuro-2a cells were exposed to OGD, NOR-1 siRNA and a combination of OGD and siRNA for 6 hours. Control cells received Scrambled siRNA as the negative control. Cell viability was assayed with a colorimetric method (A). Caspase-3 activity was analyzed using a fluorometric substrate assay (B). DNA fragmentation was quantified using an ELISA method (C). Apoptotic cells were quantified using a flow cytometer (D). Each value represents the mean \pm SEM $(n=6)$. ${ }^{*}$ Values significantly $(p<0.05)$ differed from those of the control and OGD-treated groups, respectively.

OGD-induced CREB can regulate NOR-1 gene expression and that augmented NOR-1 can function as an early-response protein to transduce survival signals in neuronal cells by transcriptionally regulating $c I A P 2$ gene expression in response to hypoxic stress. Clinically, NOR-1 has potential as an effective biomarker for diagnosis and prognosis of hypoxia-related brain diseases such as TBI and brain tumors.

\section{Acknowledgments}

We thank Ms. Yi-Ling Lin for data collection and technical help with this manuscript.

This project was supported by grants from the Chi-Mei Medical Center (101CM-TMU-13-2), Wan-Fang Hospital (101-wfeva-15), the National Science Council (NSC101-2314-B-038-003MY3), and Health and Welfare Surcharge of Tobacco Products (MOHW103-TD-B-111-01).

\section{References}

1. Axelson H, Fredlund E, Ovenberger M, Landberg G, Påhlman S: Hypoxia-induced dedifferentiation of tumor cells-a mechanism behind heterogeneity and aggressiveness of solid tumors. Semin Cell Dev Biol 16:554-563, 2005
2. Barco A, Marie H: Genetic approaches to investigate the role of CREB in neuronal plasticity and memory. Mol Neurobiol 44:330-349, 2011

3. Chang HC, Chen TG, Tai YT, Chen TL, Chiu WT, Chen RM: Resveratrol attenuates oxidized LDL-evoked Lox-1 signaling and consequently protects against apoptotic insults to cerebrovascular endothelial cells. J Cereb Blood Flow Metab 31:842-854, 2011

4. Chang HC, Tai YT, Cherng YG, Lin JW, Liu SH, Chen TL, et al: Resveratrol attenuates high-fat diet-induced disruption of the blood-brain barrier and protects brain neurons from apoptotic insults. J Agric Food Chem 62:3466-3475, 2014

5. Chen RM, Tai YT, Chen TG, Lin TH, Chang HC, Chen TL, et al: Propofol protects against nitrosative stress-induced apoptotic insults to cerebrovascular endothelial cells via an intrinsic mitochondrial mechanism. Surgery 154:58-68, 2013

6. Chesnut RM, Marshall LF, Klauber MR, Blunt BA, Baldwin $\mathrm{N}$, Eisenberg HM, et al: The role of secondary brain injury in determining outcome from severe head injury. J Trauma 34:216-222, 1993

7. Chio CC, Lin JW, Cheng HA, Chiu WT, Wang YH, Wang JJ, et al: MicroRNA-210 targets antiapoptotic Bcl-2 expression and mediates hypoxia-induced apoptosis of neuroblastoma cells. Arch Toxicol 87:459-468, 2013 
8. Chuang CY, Chen TL, Cherng YG, Tai YT, Chen TG, Chen RM: Lipopolysaccharide induces apoptotic insults to human alveolar epithelial A549 cells through reactive oxygen species-mediated activation of an intrinsic mitochondriondependent pathway. Arch Toxicol 85:209-218, 2011

9. Chuang CY, Chen TG, Tai YT, Chen TL, Lin YH, Tsai CH, et al: Toll-like receptor 2-mediated sequential activation of MyD88 and MAPKs contributes to lipopolysaccharideinduced $s p$ - $a$ gene expression in human alveolar epithelial cells. Immunobiology 216:707-714, 2011

10. Eftedal I, Jørgensen A, Røsbjørgen R, Flatberg A, Brubakk AO: Early genetic responses in rat vascular tissue after simulated diving. Physiol Genomics 44:1201-1207, 2012

11. Fatemi A, Wilson MA, Johnston MV: Hypoxic-ischemic encephalopathy in the term infant. Clin Perinatol 36:835-858, vii, 2009

12. Gerstner ER, Duda DG, di Tomaso E, Ryg PA, Loeffler JS, Sorensen AG, et al: VEGF inhibitors in the treatment of cerebral edema in patients with brain cancer. Nat Rev Clin Oncol 6:229-236, 2009

13. Goyal L: Cell death inhibition: keeping caspases in check. Cell 104:805-808, 2001

14. Jana A, Hogan EL, Pahan K: Ceramide and neurodegeneration: susceptibility of neurons and oligodendrocytes to cell damage and death. J Neurol Sci 278:5-15, 2009

15. Jensen RL: Brain tumor hypoxia: tumorigenesis, angiogenesis, imaging, pseudoprogression, and as a therapeutic target. J Neurooncol 92:317-335, 2009

16. Kagaya S, Ohkura N, Tsukada T, Miyagawa M, Sugita Y, Tsujimoto G, et al: Prostaglandin A2 acts as a transactivator for NOR1 (NR4A3) within the nuclear receptor superfamily. Biol Pharm Bull 28:1603-1607, 2005

17. Kim Y, Hong S, Noh MR, Kim SY, Huh PW, Park SH, et al: Inductin of neuron-derived orphan receptor-1 in the dentate gyrus of the hippocampal formation following transient global ischemia in the rat. Mol Cells 22:8-12, 2006

18. Kitagawa K: CREB and cAMP response element-mediated gene expression in the ischemic brain. FEBS J 274:32103217,2007

19. Liao MH, Tai YT, Cherng YG, Liu SH, Chang YA, Lin PI, et al: Genistein induces oestrogen receptor- $\alpha$ gene expression in osteoblasts through activation of mitogen-activated protein kinases/NF- $\kappa \mathrm{B} /$ activator protein-1 and promotes cell mineralisation. Br J Nutr 111:55-63, 2014

20. Lin JW, Chen JT, Hong CY, Lin YL, Wang KT, Yao CJ, et al: Honokiol traverses the blood-brain barrier and induces apoptosis of neuroblastoma cells via an intrinsic bax-mitochondrion-cytochrome c-caspase protease pathway. Neuro Oncol 14:302-314, 2012

21. Lin YL, Chang HC, Chen TL, Chang JH, Chiu WT, Lin JW, et al: Resveratrol protects against oxidized LDL-induced breakage of the blood-brain barrier by lessening disruption of tight junctions and apoptotic insults to mouse cerebrovascular endothelial cells. J Nutr 140:2187-2192, 2010

22. Lingsma HF, Roozenbeek B, Steyerberg EW, Murray GD, Maas AI: Early prognosis in traumatic brain injury: from prophecies to predictions. Lancet Neurol 9:543-554, 2010

23. Martínez-González J, Badimon L: The NR4A subfamily of nuclear receptors: new early genes regulated by growth factors in vascular cells. Cardiovasc Res 65:609-618, 2005

24. Martorell L, Gentile M, Rius J, Rodríguez C, Crespo J, Badimon L, et al: The hypoxia-inducible factor $1 /$ NOR-1 axis regulates the survival response of endothelial cells to hypoxia. Mol Cell Biol 29:5828-5842, 2009

25. Maxwell MA, Muscat GE: The NR4A subgroup: immediate early response genes with pleiotropic physiological roles. Nucl Recept Signal 4:e002, 2006

26. Mazzeo AT, Bullock R: Monitoring brain tissue oxymetry: will it change management of critically ill neurologic patients? J Neurol Sci 261:1-9, 2007
27. Montminy MR, Bilezikjian LM: Binding of a nuclear protein to the cyclic-AMP response element of the somatostatin gene. Nature 328: $175-178,1987$

28. Nomiyama T, Zhao Y, Gizard F, Findeisen HM, Heywood EB, Jones KL, et al: Deficiency of the NR4A neuron-derived orphan receptor-1 attenuates neointima formation after vascular injury. Circulation 119:577-586, 2009

29. Okouchi M, Ekshyyan O, Maracine M, Aw TY: Neuronal apoptosis in neurodegeneration. Antioxid Redox Signal 9:1059-1096, 2007

30. Østergaard L, Aamand R, Karabegovic S, Tietze A, Blicher JU, Mikkelsen IK, et al: The role of the microcirculation in delayed cerebral ischemia and chronic degenerative changes after subarachnoid hemorrhage. J Cereb Blood Flow Metab 33:1825-1837, 2013

31. Park HA, Licznerski P, Alavian KN, Shanabrough M, Jonas EA: Bcl-xL is necessary for neurite outgrowth in hippocampal neurons. Antioxid Redox Signal 22:93-108, 2015

32. Rius J, Martínez-González J, Crespo J, Badimon L: Involvement of neuron-derived orphan receptor-1 (NOR-1) in LDLinduced mitogenic stimulus in vascular smooth muscle cells: role of CREB. Arterioscler Thromb Vasc Biol 24:697-702, 2004

33. Shin HJ, Park KK, Lee BH, Moon CK, Lee MO: Identification of genes that are induced after cadmium exposure by suppression subtractive hybridization. Toxicology 191:121131,2003

34. Wang CY, Mayo MW, Korneluk RG, Goeddel DV, Baldwin AS Jr: NF-kappaB antiapoptosis: induction of TRAF1 and TRAF2 and c-IAP1 and c-IAP2 to suppress caspase- 8 activation. Science 281:1680-1683, 1998

35. Wei JD, Lin YL, Tsai CH, Shieh HS, Lin PI, Ho WP, et al: SATB2 participates in regulation of menadione-induced apoptotic insults to osteoblasts. J Orthop Res 30:1058-1066, 2012

36. Weinreb O, Mandel S, Youdim MB, Amit T: Targeting dysregulation of brain iron homeostasis in Parkinson's disease by iron chelators. Free Radic Biol Med 62:52-64, 2013

37. Wu H, Tschopp J, Lin SC: Smac mimetics and TNFalpha: a dangerous liaison? Cell 131:655-658, 2007

38. Wu TT, Tai YT, Cherng YG, Chen TG, Lin CJ, Chen TL, et al: GATA-2 transduces LPS-induced $i l-1 \beta$ gene expression in macrophages via a toll-like receptor 4/MD88/MAPK-dependent mechanism. PLoS One 8: 72404,2013

39. Zhao Y, Bruemmer D: NR4A orphan nuclear receptors: transcriptional regulators of gene expression in metabolism and vascular biology. Arterioscler Thromb Vasc Biol 30:15351541,2010

\section{Disclosures}

The authors report no conflict of interest concerning the materials or methods used in this study or the findings specified in this paper.

\section{Author Contributions}

Conception and design: RM Chen, Chio, Wei. Acquisition of data: RM Chen, Chio, TG Chen, Shieh. Analysis and interpretation of data: RM Chen, Chio, Wei, Lin, Shieh, Yeh. Drafting the article: RM Chen, Chio. Critically revising the article: RM Chen. Reviewed submitted version of manuscript: all authors. Approved the final version of the manuscript on behalf of all authors: RM Chen. Statistical analysis: RM Chen, Wei, TG Chen, Lin.

\section{Correspondence}

Ruei-Ming Chen, Graduate Institute of Medical Sciences, Taipei Medical University, 250 Wu-Xing St., Taipei 110, Taiwan. email: rmchen@tmu.edu.tw. 